\title{
Continuing Education-XVI
}

I have been asked to write a few words about continuing education for academic librarians, I suppose because the person who asked thought this question must have come up during my years on the Academic Status Committee and as a library director with an active library faculty. Right, but less often than you might think. In any event, having a few words at the ready on almost anything, I'll come CLENE on continuing ed.

There are two "in" phrases these days about library personnel-staff development is one and continuing education is the other. I have the same problem with both: I don't know what they mean. What is continuing education? Is it reading this issue of C $d R L$ News? Or the Chronicle? Or the Journal of Higher Education? Or the Times Education Supplement? Or the Times Higher Education Supplement? Is it attending a class; taking a course (auditing for credit); attending a conference, workshop, institute (with or without CEUs)? Is it talking with colleagues from across town or from across the state; visiting the Bodleian or the Vatican Library (or LC or the Folger for provincials like me who haven't gone beyond this continent); using the local public library (for the best-selling novel we academics won't deign to acquire)? Enough!

What is more important than "what it is" is whether we do it, any of it, how much, and why. To take the last first, we do it (if we do) because continuing education is part, some would say the essential part, of being a professional. To recognize that our formal professional education (library school) is the base, but that it is necessarily time-bound, however well intentioned and designed, is to acknowledge the responsibility for and the commitment of the professional to change. This professional obligation is complemented and reinforced by the three primary objectives of the academy: the preservation, dissemination, and generation of information. Philosophers will note here the word information rather than knowledge. Therein lies another debate.

Back to the point. Given the why, how much continuing education do academic librarians do? Alas, not enough, notwithstanding the fasterthan-rabbits proliferation of library organizations, but about as much as many doctors, dentists, and lawyers, judging from the stories around. In a typical academic library faculty, the same faithful few carry the committee load, attend conferences, publish, and hold offices. Another cadre measures its work by the clock, neither reading nor subscribing to any professional literature. This cohort is widely believed to be the rank and file who insure the continuation of the basic operations and services of the library. After all, everybody can't be a star, so some have to stay home and mind the store. Judging from who stays home, the marvel is the level of quality of the service provided in academic libraries, and the wonder is that this level isn't lower than it is.

There are no easy answers to how to make locals more cosmopolitan. Time, money, constant prodding, reinforcement, reward, and opportunity are a few of the necessary conditions, but above all an act of faith that continuing education (read professional activity) really makes a difference in the quality of service our libraries provide-C. James Schmidt.

Editor's Note: C. James Schmidt is university librarian at Brown University, Providence, Rhode Island.

\section{Model Mission Statement for Undergraduate Libraries}

At the 1978 Midwinter Meeting of the ACRL Undergraduate Librarians Discussion Group (UGL), a group of librarians expressed interest in writing a model statement that would define the scope and articulate the UGL purpose in the academic library.

For the past year and a half the group has met, corresponded, and worked on improving successive drafts of a mission statement. We have tried to address the key factors in the establishment of the UGL and develop a service philosophy that reflects the specific needs and the major components of an undergraduate library operation.

Librarians may use the model mission statement for comparison with their local statements, as evidence to support the purpose of the UGL, and as a starting point for continued definition and advocacy of the UGL at local and national levels. With these ends in mind, the study group has kept the text general. We have tried to provide distinctions unique to the UGL, while encouraging breadth in interpretation to suit local situations.

Copies of the Mission of an Undergraduate Library (Draft Model Statement) are available from Donna Senzig, College Library, University of Wisconsin-Madison, $600 \mathrm{~N}$. Park St. Madison, WI 53706.-Lan Dyson (Berkeley), Monty Maxwell (Bloomington, Indiana), Linda Phillips (Knoxville, Tennessee), Jay Poole (Austin, Texas), Tim Richards (Ann Arbor, Michigan), Liz Salzer (Stanford), Donna Senzig (Madison, Wisconsin), and Yorum Szekely (Cornell). 